\title{
Analysis of Adenosine Triphosphate and Glutathione through Gold Nanoparticles Assisted Laser Desorption/Ionization Mass Spectrometry
}

\author{
Yu-Fen Huang ${ }^{\dagger}$ and Huan-Tsung Chang*,t,f \\ Department of Chemistry, National Taiwan University, 1, Section 4, Roosevelt Road, Taipei 106, Taiwan, and Department of \\ Natural Science Education, National Taitung University, Taitung, Taiwan
}

This paper describes the use of aptamer-modified gold nanoparticles (Apt-AuNPs) as selective probes and AuNPs as the surface-assisted laser desorption/ionization (SALDI) matrixes for the determination of adenosine triphosphate (ATP) by mass spectrometry (MS). The aptamers were covalently attached to the surface of AuNPs to form Apt-AuNPs that provided selectivity toward ATP. However, Apt-AuNPs are less efficient laser desorption/ ionization (LDI) matrixes when compared to AuNPs. By using Apt-AuNPs as selective probes and AuNPs as LDI matrixes, the MS approach provided the limit of detection (LOD) for ATP at a signal-to-noise ratio of 3 of $0.48 \mu \mathrm{M}$. When compared to conventional organic matrixes (e.g., 2,5-dihydroxybenzoic acid), AuNPs as LDI matrixes provide a number of advantages, including ease of preparation, selectivity, sensitivity, and repeatability. Sequential analysis of ATP and GSH in human cell lysates by SALDI with negative and positive MS modes, respectively, using Apt-AuNPs and AuNPs has been demonstrated. The present results demonstrate the practicality of the approach for monitoring the bioactivity of cells through determinations of the concentrations of ATP and GSH.

Matrix-assisted laser desorption/ionization mass spectrometry (MALDI-MS) has become a powerful tool for biochemical analysis ${ }^{1-3}$ since its inception in $1987 .{ }^{4}$ As a result of rapid energy transfer from UV-absorbing matrixes, analytes undergo soft and efficient desorption/ionization with a minimum degree of fragmentation. ${ }^{5-7}$ Although MALDI-MS is successfully used for the analyses

* Author to whom correspondence should be addressed. Phone and Fax: 011886-2-33661171. E-mail: changht@ntu.edu.tw.

$\dagger$ National Taiwan University.

* National Taitung University.

(1) Cramer, R.; Gobom, J.; Nordhoff, E. Expert Rev. Proteomics 2005, 2, 407420.

(2) Reyzer, M. L.; Caprioli, R. M. J. Proteome Res. 2005, 4, 1138-1142.

(3) Tost, J.; Gut, I. G. Clin. Biochem. 2005, 38, 335-350.

(4) Karas, M.; Hillenkamp, F. Anal. Chem. 1988, 60, 2299-2301.

(5) Alexander, M. L.; Hemberger, P. H.; Cisper, M. E.; Nogar, N. S. Anal. Chem. 1993, 65, 1609-1614.

(6) Schlag, E. W.; Grotemeyer, J.; Levine, R. D. Chem. Phys. Lett. 1992, 190, 521-527.

(7) Glish, G. L.; Goeringer, D. E.; Asano, K. G.; McLuckey, S. A. Int. J. Mass Spectrom. Ion Processes 1989, 94, 15-24. of varieties of molecules, especially peptides and proteins, ${ }^{1,8}$ it has never been popular for the characterization of low-molecularweight compounds $(<500 \mathrm{~g} / \mathrm{mol})$. The challenge is due in part to the presence of a variety of abundant matrix-related ions in the low-mass range of MS spectra. In addition, the inhomogeneous cocrystallization of analytes with traditional organic matrixes, such as 2,5-dihydroxybenzoic acid (DHB) and sinapinic acid (SA), usually leads to the existence of "sweet spots" on the sample probe, which sometimes causes quantitative errors. These disadvantages have hindered efforts to utilize the full power of MALDIMS for high-throughput analyses of drugs and their metabolites from complex mixtures containing high concentrations of salts. ${ }^{9-11}$ To overcome the problems, surface-assisted laser desorption/ ionization (SALDI)-MS has been exerted to eliminate matrix ion interference and to improve sample homogeneity. ${ }^{12-22}$ Useful SALDI matrixes include ultrafine cobalt powders, ${ }^{12}$ micrometersized graphite particles, ${ }^{13,14}$ porous silicon surface, ${ }^{15-17,22}$ and other inorganic materials. ${ }^{18-20}$

Recently, nanoparticles (NPs) have been recognized as effective SALDI matrixes because of their high surface areas, ease of sample preparation, flexibility of sample deposition, and high UV

(8) Areces, L. B.; Matafora, V.; Bachi, A. Eur. J. Mass Spectrom. 2004, 10, 383392.

(9) Brown, R. S.; Lennon, J. J. Anal. Chem. 1995, 67, 1998-2003.

(10) Vestal, M. L.; Juhasz, P.; Martin, S. A. Rapid Commun. Mass Spectrom. 1995, 9, 1044-1050.

(11) Cohen, L. H.; Gusev, A. I. Anal. Bioanal. Chem. 2002, 373, 571-586.

(12) Tanaka, K.; Waki, H.; Ido, Y.; Akita, S.; Yoshida, Y.; Yoshida, T. Rapid Commun. Mass Spectrom. 1988, 2, 151-153.

(13) Dale, M. J.; Knochenmuss, R.; Zenobi, R. Anal. Chem. 1996, 68, 33213329.

(14) Sunner, J.; Dratz, E.; Chen, Y.-C. Anal. Chem. 1995, 67, 4335-4342.

(15) Wei, J.; Buriak, J. M.; Siuzdak, G. Nature 1999, 399, 243-246.

(16) Kruse, R. A.; Li, X.; Bohn, P. W.; Sweedler, J. V. Anal. Chem. 2001, 73, $3639-3645$.

(17) Finkel, N. H.; Prevo, B. G.; Velev, O. D.; He, L. Anal. Chem. 2005, 77, $1088-1095$.

(18) Kinumi, T.; Saisu, T.; Takayama, M.; Niwa, H. J. Mass Spectrom. 2000, 35, $417-422$.

(19) Schürenberg, M.; Dreisewerd, K.; Hillenkamp, F. Anal. Chem. 1999, 71, 221-229.

(20) Guo, Z.; Ganawi, A. A. A.; Liu, Q.; He, L. Anal. Bioanal. Chem. 2006, 384, $584-592$.

(21) Black, C.; Poile, C.; Langley, J.; Herniman, J. Rapid Commun. Mass Spectrom. 2006, 20, 1053-1060.

(22) Budimir, N.; Blais, J.-C.; Fournier, F.; Tabet, J.-C. Rapid Commun. Mass Spectrom. 2006, 20, 680-684.

10.1021/ac070023x CCC: $\$ 37.00$ @ 2007 American Chemical Society Published on Web 05/25/2007 
absorptivity. ${ }^{19,20,23}$ The species of NPs and suspended liquids are important parameters for determining the MS sensitivity and selectivity. For example, $\mathrm{Fe}_{3} \mathrm{O}_{4} / \mathrm{TiO}_{2}$ core/shell NPs are selective toward phosphopeptides and useful matrixes for the analysis of proteins with the masses up to 24000 Da by SALDI-MS. ${ }^{24}$ In order to further improve the selectivity, a variety of readily available approaches are employed for anchoring molecules to the nanoscale surface to form versatile and covalently stable conjugated NPs that are extremely specific to target analytes. ${ }^{25-30}$ For instance, vancomycin that has high specificity for the D-Ala-D-Ala units of cell walls was immobilized on magnetic NPs. These functionalized magnetic NPs have been employed as affinity probes to selectively trap Gram-positive bacteria from urine samples prior to MALDIMS measurements. ${ }^{26}$ Two antibodies-conjugated magnetic NPs have been demonstrated as efficient affinity captures for C-reactive protein and serum amyloid $\mathrm{P}$ from diluted human plasma prior to MALDI-MS measurements. ${ }^{31}$ Other examples include polylysine-conjugated diamond nanocrystals, ${ }^{32}$ citrate-stabilized Au@magnetic particles, ${ }^{33}$ tetraalkylammonium-stabilized AuNPs, ${ }^{34}$ carboxylated/oxidized diamond NPs, ${ }^{35}$ and alkyl-chain-modified superparamagnetic, silica-based particles ${ }^{36}$ for selective captures of oligonucleotides, proteins, and/or peptides through hydrophilic and/or hydrophobic patches. Although those representatives demonstrated that bioconjugated NPs are selective toward target analytes, nonspecific adsorption is commonly found in the analysis of complicated biological samples such as blood. In order to minimize nonspecific interactions of bioconjugated NPs with interferences, modification of their surfaces with short methoxyethyl-terminated ethylene glycol has been suggested to be effective. $^{28}$

The utility of AuNPs as SALDI matrixes has been recently examined by McLean et $\mathrm{al}^{23}$ When using 2-10 $\mathrm{nm}$ diameter AuNPs as SALDI matrixes, a number of peptides including substance $\mathrm{P}$ and small proteins like bovine insulin are detectable through MS. In addition to the role of SALDI matrixes, AuNPs afford a degree of selectivity: preferential ionization of phosphotyrosine-containing peptides over phosphoserine- or phosphothreonine-containing ones. More recently, the use of Nile-redbound AuNPs as selective probes and matrixes for the determina-

(23) McLean, J. A.; Stumpo, K. A.; Russell, D. H. J. Am. Chem. Soc. 2005, 127, 5304-5305.

(24) Chen, C.-T.; Chen, Y.-C. Anal. Chem. 2005, 77, 5912-5919.

(25) Dick, L. W.; McGown, L. B. Anal. Chem. 2004, 76, 3037-3041.

(26) Lin, Y.-S.; Tsai, P.-J.; Weng, M.-F.; Chen, Y.-C. Anal. Chem. 2005, 77, 17531760.

(27) Turney, K.; Drake, J. T.; Smith, E. J.; Tan, W.; Harrison, W. W. Rapid Commun. Mass Spectrom. 2004, 18, 2367-2374.

(28) Lin, P.-C.; Chou, P.-H.; Chen, S.-H.; Liao, H.-K.; Wang, K.-Y.; Chen, Y.-J.; Lin, C.-C. Small 2006, 2, 485-489.

(29) Cole, J. R.; Dick, L. W.; Morgan, E. J.; McGown, L. B. Anal. Chem. 2007, 79, 273-279.

(30) Vanderpuije, B. N. Y.; Han, G.; Rotello, V. M.; Vachet, R. W. Anal. Chem. 2006, 78, 5491-5496.

(31) Chou, P.-H.; Chen, S.-H.; Liao, H.-K.; Lin, P.-C.; Her, G.-R.; Lai, A. C.-Y.; Chen, J.-H.; Lin, C.-C.; Chen, Y.-J. Anal. Chem. 2005, 77, 5990-5997.

(32) Kong, X.; Huang, L. C. L.; Liau, S.-C. V.; Han, C.-C.; Chang, H.-C. Anal. Chem. 2005, 77, 4273-4277.

(33) Teng, C.-H.; Ho, K.-C.; Lin, Y.-S.; Chen, Y.-C. Anal. Chem. 2004, 76, $4337-$ 4342.

(34) Sudhir, P.-R.; Wu, H.-F.; Zhou, Z.-C. Anal. Chem. 2005, 77, 7380-7385.

(35) Kong, X. L.; Huang, L. C. L.; Hsu, C.-M.; Chen, W.-H.; Han, C.-C.; Chang, H.-C. Anal. Chem. 2005, 77, 259-265.

(36) Villanueva, J.; Philip, J.; Entenberg, D.; Chaparro, C. A.; Tanwar, M. K.; Holland, E. C.; Tempst, P. Anal. Chem. 2004, 76, 1560-1570. tion of glutathione (GSH), cysteine, and homocysteine through SALDI-MS has been demonstrated. ${ }^{37}$ The simple approach allows the analyses of GSH in red blood cells and of cysteine in plasma, with the advantages of sensitivity and reproducibility. However, the probe is only practical for thiol compounds that bind AuNPs strongly through $\mathrm{Au}-\mathrm{S}$ bonding.

Our goal in this study aims at developing highly selective probe and effective SALDI matrixes for the determination of small molecules such as adenosine triphosphate (ATP) and GSH by MS, with the advantages of small variations, sensitivity, simplicity, and selectivity. Such a SALDI-MS approach is important for diagnosis and should pave the road for developing novel techniques to obtain the MS images of single cells. ATP and GSH are two important substrates in living organisms and have been used as indicators for cell viability and cell injury. ${ }^{38,39}$ Unlike GSH, ATP does not bind specifically with AuNPs. Thus, we prepared aptamer-modified AuNPs (Apt-AuNPs) to facilitate the concentration of ATP from complicated samples such as cells. Aptamers are nucleotides typically having a size between 15 and 70 bases in length and are combinatorially selected in vitro by systematic evolution of ligands by exponential enrichment (SELEX). ${ }^{40,41}$ The DNA-based ATP aptamer ${ }^{42}$ used in this study binds two ATP molecules in a noncanonical, but stable, helix comprised of G:G and G:A base pairs flanked by short canonical helices. ${ }^{43}$ In this study, we carefully evaluated important parameters such as the $\mathrm{pH}$ and ionic strength of the solutions and the concentration of sample additives on the determinations of ATP and GSH. To demonstrate its practicality, the present approach was applied to determination of ATP and GSH in human lysed cells.

\section{EXPERIMENTAL SECTION}

Chemicals. Sodium tetrachloroaurate(III) dehydrate, GSH, ATP, guanosine triphosphate, cytidine triphosphate, and uridine triphosphate, 2' $4^{\prime} 6^{\prime}$-trihydroxyactophenone, and 3-hydroxypicolinic acid were obtained from Sigma (St. Louis, MO). Citric acid, trisodium citrate, and DHB were purchased from Aldrich (Milwaukee, WI). Ammonium hydroxide, potassium chloride, magnesium chloride, and CTAB, $98 \%$ were obtained from Acros (Geel, Belgium). The 5'-thiol-modified aptamer having the sequence 5'-TTT TTT ACC TGG GGG AGT ATT GCG GAG GAA GGT-3' was purchased from Purigo Biotech, Inc. (Taipei, Taiwan). When $100.0 \mathrm{mM}$ citric acid was used to prepare citrate solutions (0.5 mM, pH 4.0-10.0), $\mathrm{NH}_{4} \mathrm{OH}(25-30 \%)$ was used to adjust their $\mathrm{pH}$ values.

Synthesis of AuNPs. AuNPs were prepared by citrate reduction of $\mathrm{NaAuCl}_{4} \cdot{ }^{4}$ A $250 \mathrm{~mL}$ aqueous solution consisting of $1.0 \mathrm{mM} \mathrm{NaAuCl}{ }_{4}$ was brought to a vigorous boil while being stirred in a round-bottom flask fitted with a reflux condenser, and then $38.8 \mathrm{mM}$ trisodium citrate $(25.0 \mathrm{~mL})$ was added rapidly to the solution. The solution was boiled for another 15 min, during

(37) Huang, Y.-F.; Chang, H.-T. Anal. Chem. 2006, 78, 1485-1493.

(38) Atkinson, D. E. Cellular Energy Metabolism and Its Regulations; Academic Press: New York, 1977.

(39) Pérez-Ruiz, T.; Martínez-Lozano, C.; Tomás, V.; Martín, J. Anal. Bioanal. Chem. 2003, 377, 189-194.

(40) Tuerk, C.; Gold, L. Science 1990, 249, 505-510.

(41) Green, R.; Ellington, A. D.; Szostak, J. W. Nature 1990, 347, 406-408.

(42) Huizenga, D. E.; Szostak, J. W. Biochemistry 1995, 34, 656-665.

(43) Lin, C. H.; Patel, D. J. Chem. Biol. 1997, 4, 817-832.

(44) Frens, G. Nat. Phys. Sci. 1973, 241, 20-22. 
which time its color changed from pale-yellow to wine-red. The solution was cooled to room temperature with continuous stirring. The sizes of the AuNPs were verified by TEM measurements using an H7100 TEM from Hitachi (Tokyo, Japan) operated at 75 $\mathrm{kV}$; they appeared to be nearly monodispersed, with an average size of $13.3 \pm 1.2 \mathrm{~nm}$. A double-beam UV-vis spectrophotometer (Cintra 10e) obtained from GBC (Victoria, Australia) was used to measure the absorbance of the AuNPs in citrate solutions. The UV-vis absorption measurements (not shown) indicated that the maximum wavelengths of the surface plasmon resonance were $520 \mathrm{~nm}$. The particle concentration of the AuNPs was $13.0 \mathrm{nM}$, which was determined according to Beer's law using the extinction coefficient of $\sim 10^{8} \mathrm{M}^{-1} \mathrm{~cm}^{-1}$ for $13.3 \mathrm{~nm}$ AuNPs in diameter at $520 \mathrm{~nm} .{ }^{45}$ In this paper, we denote the concentration of the asprepared AuNPs to be $1 \times$ for the sake of simplicity. When AuNPs were used as SALDI matrix, they were concentrated by centrifugation at $16000 \mathrm{rpm}$ for $10 \mathrm{~min}$. The precipitates were then resuspended in $0.5 \mathrm{mM}$ citrate solution $(\mathrm{pH} 4.0)$ to make the final concentration of $1.5 \times$, which was estimated from the ratio of its absorbance value at $520 \mathrm{~nm}$ to that of the $1 \times$ AuNPs. $^{46}$

Synthesis of Apt-AuNPs. The thiol-modified 33-mer DNA oligonucleotides were attached to the AuNPs according to modified literature procedures. ${ }^{47}$ The 5 '-thiol-modified oligonucleotides were reacted directly with the AuNPs through attachment of the oligo-S- units onto the AuNP surface. An aliquot of aqueous AuNP solution $(985.0 \mu \mathrm{L})$ in a $1.5 \mathrm{~mL}$ tube was mixed with the thio-oligonucleotides $(100.0 \mu \mathrm{M}, 15.0 \mu \mathrm{L})$ to obtain a final concentration of ca. $1 \times$ AuNPs and $1.5 \mu \mathrm{M}$ oligonucleotides. After reaction for $12 \mathrm{~h}$ at room temperature, the mixtures were centrifuged for $20 \mathrm{~min}$ at $18000 \mathrm{rpm}$ to remove the excess thiolDNA. Following removal of the supernatants, the oily precipitates were washed with $4.0 \mathrm{mM}$ trisodium citrate. After two centrifugation-washing cycles, the colloids were resuspended in $4.0 \mathrm{mM}$ trisodium citrate $(0.2 \mathrm{~mL})$ and stored in a refrigerator $\left(4^{\circ} \mathrm{C}\right)$. The concentration of the as-prepared Apt-AuNPs is ca. $5 \times$. To determine the number of oligos on each AuNP, a solution of 2-mercaptoethanol $(1.0 \mathrm{M}, 10.0 \mu \mathrm{L})$ was used to displace the oligonucleotide molecules from the surface of AuNPs $(13.0 \mathrm{nM}$, $990.0 \mu \mathrm{L}$ ). The concentration of displaced oligonucleotide molecules in the supernatant was stained by oligreen (Quant-iT OliGreen ssDNA reagent, Molecular Probe, Eugene, Oregon). The fluorescence intensities at $538 \mathrm{~nm}$ were converted to molar concentrations of the thiol-modified oligonucleotide by interpolation from a standard linear calibration curve, and the calculations indicated that ca. 90 oligonucleotide molecules were attached to each AuNP. ${ }^{48}$

Preparation of Samples. ATP $(10.0 \mu \mathrm{L}, 0.5 \mu \mathrm{M}$ to $2.0 \mathrm{mM})$ were added separately to $3.0 \times \operatorname{AuNP}(10.0 \mu \mathrm{L})$ solutions and equilibrated for $1 \mathrm{~h}$. Sample mixtures (ca. $1.0 \mu \mathrm{L}$ ) were pipetted into a stainless-steel 384-well MALDI target (Bruker Daltonics). Aliquots of $1.0 \mu \mathrm{L}$ of ammonium citrate $(0-50.0 \mathrm{mM})$ at $\mathrm{pH}$ values ranging from 4.0-10.0 were separately deposited on the MALDI

(45) Mucic, R. C.; Storhoff, J. J.; Mirkin, C. A.; Letsinger, R. L. J. Am. Chem. Soc. 1998, 120, 12674-12675.

(46) Huang, M.-F.; Kuo, Y.-C.; Huang, C.-C.; Chang, H.-T. Anal. Chem. 2004, $76,192-196$.

(47) Storhoff, J. J.; Elghanian, R.; Mucic, R. C.; Mirkin, C. A.; Letsinger, R. L. J. Am. Chem. Soc. 1998, 120, 1959-1964.

(48) Demers, L. M.; Mirkin, C. A.; Mucic, R. C.; Reynolds, R. A.; Letsinger, R. L.; Elghanian, R.; Viswanadham, G. Anal. Chem. 2000, 72, 5535-5541. target wells and mixed with the sample mixtures by pipetting. The mixtures were dried in air at room temperature prior to SALDI-MS measurements. In the case where DHB $(20.0 \mathrm{mg} / \mathrm{mL}$ in water) was used as a matrix for MALDI-MS analysis, DHB $(1.0 \mu \mathrm{L})$ was mixed with $0.2 \mathrm{mM}$ ATP $(1.0 \mu \mathrm{L})$ in the well of the steel plate and dried in air at room temperature prior to MALDIMS measurements.

ATP Capture and Analysis. We first prepared a $1.25 \times$ folding buffer $(1.0 \mathrm{~mL})$, which consisted of $20.0 \mathrm{mM}$ Tris- $\mathrm{HCl}$ buffer $(\mathrm{pH}$ 7.6) containing $17.5 \mathrm{mM} \mathrm{KCl}, 5.0 \mathrm{mM} \mathrm{MgCl}$. Then, $2.5 \mu \mathrm{L}$ of ATP solutions and $2.5 \mu \mathrm{L}$ of Apt-AuNPs were added to the $1.25 \times$ folding buffers $(20.0 \mu \mathrm{L})$; the final concentrations of ATP are 0.01-1.0 mM and those for Apt-AuNPs and folding buffers are $5 \times$ and $1 \times$, respectively. The mixtures were maintained at room temperature for $2 \mathrm{~h}$ reaction. The mixtures were then subjected to centrifugation at $8000 \mathrm{rpm}$ for $10 \mathrm{~min}$. Following removal of the supernatants, the precipitates were washed with the folding buffer $(50.0 \mu \mathrm{L})$. After three centrifugation-washing cycles, the pellets were resuspended in $0.5 \mathrm{mM}$ citrate solutions $(\mathrm{pH} 4.0$, $20.0 \mu \mathrm{L}$ ) containing $1.5 \times$ AuNPs. The mixtures were then equilibrated at room temperature for ca. $10 \mathrm{~min}$ before centrifugation (8000 rpm, $10 \mathrm{~min}$ ). Unless otherwise noted, the pellets, obtained after removal of the supernatants were redispersed in $20.0 \mu \mathrm{L}$ citrate solutions (15.0 mM, pH 6.0) containing $15.0 \mu \mathrm{M}$ CTAB. A portion of the samples (ca. $1.0 \mu \mathrm{L}$ ) was pipetted into a stainless-steel 384-well MALDI target and dried in air at room temperature prior to the SALDI-MS measurements.

Preparation of ATP Extracts from Cultured Cells. The breast cancer cells, MDA-MB-231 adenocarcinoma, breast pleural, were cultured in cell flasks according to the instructions of the American Type Cell Culture. After the cell line was grown to $90 \%$ confluence in Leibovitz's L-15 medium, supplemented with $10 \%$ fetal calf serum at $37{ }^{\circ} \mathrm{C}$, cells were harvested by trypsinization. A suspension of $\sim 10^{6}$ cells $(10.0 \mathrm{~mL})$ was centrifuged $(3000 \mathrm{rpm}$, $7 \mathrm{~min}$ ) and washed with phosphate-buffered saline $(18.6 \mathrm{mM}$ phosphate, $4.2 \mathrm{mM} \mathrm{KCl}$, and $154.0 \mathrm{mM} \mathrm{NaCl}$ ) five times and resuspended in $0.25 \mathrm{~mL}$ of deionized water. The cells were then disrupted by sonication for $20 \mathrm{~min}$ at $0{ }^{\circ} \mathrm{C}$. To remove the homogenate of cell debris, the lysate was centrifuged at $18000 \mathrm{rpm}$ for $20 \mathrm{~min}$ at $4^{\circ} \mathrm{C}$. The supernatant was collected and deproteinized through Amicon YM10 membrane (Millipore Corp., Bedford, MA). Apt-AuNPs (final concentration: $5 \times$ ) were added to the filtrate $(25.0 \mu \mathrm{L})$, and the mixtures were incubated at room temperature for $2 \mathrm{~h}$. The ATP/Apt-AuNP mixtures were then subjected to three cycles of centrifugation at $8000 \mathrm{rpm}$ for $10 \mathrm{~min}$ and washed with the folding buffer $(50.0 \mu \mathrm{L})$. The pellets were then redispersed in $0.5 \mathrm{mM}$ citrate solution $(20.0 \mu \mathrm{L}, \mathrm{pH} 4.0)$ containing $1.5 \times$ AuNPs and equilibrated for $10 \mathrm{~min}$. The mixtures were then subjected to centrifugation and dispersed in $20.0 \mu \mathrm{L}$ citrate solutions (15.0 mM, pH 6.0) containing $15.0 \mu \mathrm{M}$ CTAB as described previously; portions of the samples were deposited on the target plate prior to SALDI-MS analysis.

SALDI-TOF MS Measurements. Mass spectrometry experiments were performed in either the positive- or negative-ion mode on a reflectron-type time-of-flight (TOF) mass spectrometer (Biflex III, Bruker, Germany) equipped with a $1.25 \mathrm{~m}$ flight tube. The samples were irradiated with a $337 \mathrm{~nm}$ diameter nitrogen laser at $10 \mathrm{~Hz}$ (pulse duration: $4 \mathrm{~ns}$ ). Ions produced by laser desorption 


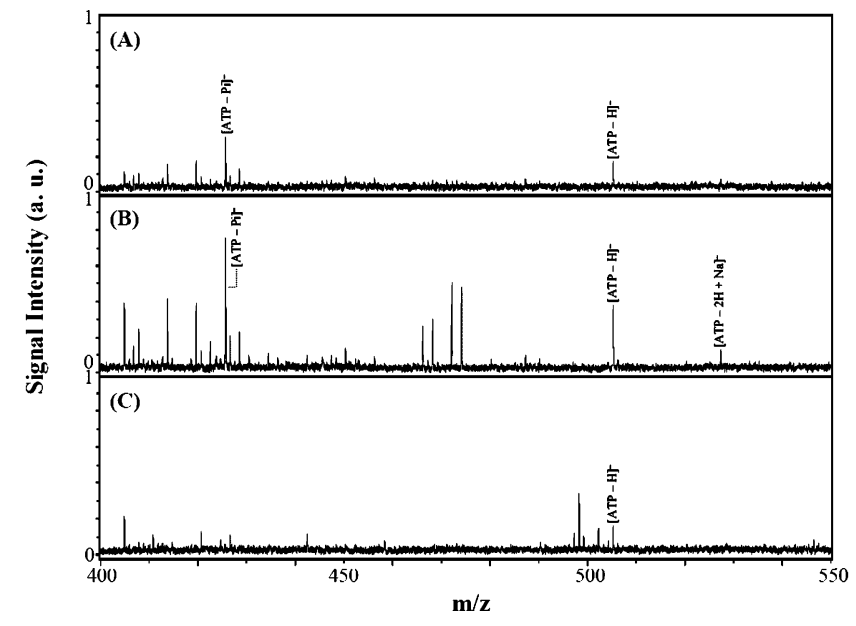

Figure 1. Mass spectra of ATP $(0.1 \mathrm{mM})$ with matrixes of (A and B) AuNPs $(1.5 \times)$ and $(C)$ DHB $(10.0 \mathrm{mg} / \mathrm{mL})$, respectively. The sample solutions were prepared in ammonium citrate solutions (15.0 mM, pH 6.0) (A) without and (B and C) with $15.0 \mu \mathrm{M}$ CTAB. The peaks at $m / z 426.20,506.18$, and 528.16 are assigned to the [ATP $-\mathrm{Pi}]^{-}$, [ATP $\left.-\mathrm{H}\right]^{-}$, and $[\text {ATP }-2 \mathrm{H}+\mathrm{Na}]^{-}$ions. A total of 80 pulsed laser shots were applied under a laser energy set at $67.5 \mu \mathrm{J} /$ pulse.

were stabilized energetically during a delayed extraction period of $200 \mathrm{~ns}$ and then accelerated through the linear TOF reflection before entering the mass analyzer. The available accelerating voltages existed in the range from +20 to $-20 \mathrm{kV}$. To obtain good resolution and signal-to-noise ratios, the laser fluence was adjusted to slightly higher than the threshold and each mass spectrum was generated by an average of 80 laser pulses.

\section{RESULTS AND DISCUSSION}

AuNPs as Assisted Matrixes for Determination of ATP. On the basis of the fact that the analytes have to be adsorbed on the AuNP surface to achieve high laser desorption/ionization (LDI) efficiency, ${ }^{37}$ it is our expectation that AuNPs are useful SALDI matrixes for ATP measurements because they have interactions through $\mathrm{Au}-\mathrm{N}$ bonding. ${ }^{49,50}$ By mixing $10.0 \mu \mathrm{L}$ of ATP $(0.2 \mathrm{mM})$ with $10.0 \mu \mathrm{L}$ of AuNPs $(3.0 \times)$, we prepared the ATP samples for MS measurements. Because ATP possesses phosphate moieties and tends to form negative charges under physiological conditions, negative MS mode was applied for the determination of ATP when using AuNPs. In addition to better sensitivity than positive mode MS, negative mode MS can avoid the plague of complicated cationic adducts formation. ${ }^{51,52}$ The MS spectrum depicted in Figure 1A displays two apparent peaks at $m / z 426.20$ and 506.18 that correspond to [ATP $-\mathrm{Pi}]^{-}$and [ATP $-\mathrm{H}]^{-}$, respectively. We point out that positive mode MS did not provide any signals for ATP ions and its fragment ions. In order to improve LDI efficiency, $20.0 \mu \mathrm{L}$ of hexadecyltrimethylammonium bromide (CTAB, $30.0 \mu \mathrm{M}$ ) was added to the sample solution containing AuNPs. In addition to greater peak intensities for the

(49) Demers, L. M.; Östblom, M.; Zhang, H.; Jang, N.-H.; Liedberg, B.; Mirkin, C. A. J. Am. Chem. Soc. 2002, 124, 11248-11249.

(50) Storhofff, J. J.; Elghanian, R.; Mirkin, C. A.; Letsinger, R. L. Langmuir 2002 18, 6666-6670.

(51) Nordhoff, E.; Kirpekar, F.; Roepstorff, P. Mass Spectrom. Rev. 1996, 15, 67-138.

(52) Edwards, J. L.; Kennedy, R. T. Anal. Chem. 2005, 77, 2201-2209. two peaks assigned for $[\mathrm{ATP}-\mathrm{Pi}]^{-}$and $[\mathrm{ATP}-\mathrm{H}]^{-}$, a small peak at $m / z 528.16$ that is assigned to be for [ATP $-2 \mathrm{H}+\mathrm{Na}^{-}$ was detected as displayed in Figure $1 \mathrm{~B}$. The electrostatic interactions between ATP (anionic) and $\mathrm{CTA}^{+}$(cationic) that possesses high surface activity lead to easy access of ATP to the AuNP surface and thus improve MS signal intensities (i.e., about 3-fold increases in the signal for $\left.[\mathrm{ATP}-\mathrm{Pi}]^{-}\right) .^{53,54}$ The minimum laser energy required per pulse to achieve peak intensity of the signalto-noise ratio $(\mathrm{S} / \mathrm{N})>3$ can also be attenuated down to $57.0 \mu \mathrm{J} /$ pulse. In the presence of CTAB, the MS resolution of [ATP $\mathrm{H}]^{-}$increases from 3080 to 4070 , likely due to cool ions generation..$^{55}$ The property of easy desorption of the analyte in the presence of $\mathrm{CTAB}$ reduces the occurrence of hot matrixes and thus provides less generation of plumes, and the ions experience less collisions. For comparison, the MS spectrum for ATP using $\mathrm{DHB}$ as MALDI matrix is depicted in Figure 1C. Only the peak corresponding to $[\mathrm{ATP}-\mathrm{H}]^{-}$was detected. Other commonly used MALDI matrixes such as $2^{\prime} 4^{\prime} 6^{\prime}$-trihydroxyactophenone and 3-hydroxypicolinic acid were also utilized for negative-ion detection, but no signals derived from ATP were detected. The facts of low signal intensities, poor repeatability, and high laser energy $(64.0 \mu \mathrm{J} /$ pulse) required when using DHB demonstrate the superiority of SALDI using AuNPs over MALDI using DHB. AuNPs providing greater LDI efficiency is likely because energy transfer from the AuNPs to the analyte occurred through a thermally driven process. ${ }^{12}$ We emphasize that the energy (light) absorption of AuNPs throughout the near-UV to near-IR ranges can be easily tuned by controlling their sizes and shapes. Thus, we suggest that SALDI-MS measurements of the sample solutions containing AuNPs and CTAB may be conducted using visible and IR lasers. ${ }^{19}$

Parameters Optimization for SALDI-MS Analysis. One disadvantage of using AuNPs as SALDI matrixes is the detection of alkali ion adducts. The source of sodium ions is from the sodium citrate and gold salt that were used for the preparation of AuNPs. To overcome the disadvantage while preparing stable AuNPs, ammonium citrate was used to wash out sodium ions from the AuNPs. ${ }^{56,57}$ Through increasing the concentration of ammonium citrate $(0-10.0 \mathrm{mM})$, the MS signals for the ATP ions increase as exhibited in Figure S1A (in the Supporting Information). The increased MS signal intensities are mainly due to the improved stability of ATP-adsorbed AuNPs; greater surface ATP molecules are accessible to ionization by laser irradiation. However, as the concentration of ammonium citrate is above $15.0 \mathrm{mM}$, the ionization efficiency of ATP begins to decrease. With increasing citrate concentration, ATP adsorbed on the AuNP surfaces is displaced by citrate to a greater degree, and thus all the signal intensities for the three ions decrease. Ionization suppression due to increased ionic strength in the system is another contributor to decreased MS signals. At $15.0 \mathrm{mM}$ ammonium citrate, the peak intensity ratio of $[\text { ATP }-\mathrm{H}]^{-} /[\mathrm{ATP}-2 \mathrm{H}+\mathrm{Na}]^{-}$reached a

(53) Chen, Y.-C.; Tsai, M.-F. J. Mass Spectrom. 2000, 35, 1278-1284.

(54) Nordström, A.; Apon, J. V.; Uritboonthai, W.; Go, E. P.; Siuzdak, G. Anal. Chem. 2006, 78, 272-278.

(55) Guo, Z.; Zhang, Q.; Zou, H.; Guo, B.; Ni, J. Anal. Chem. 2002, 74, 16371641.

(56) Pieles, U.; Zürcher, W.; Schär, M.; Moser, H. E. Nucleic Acids Res. 1993 21, 3191-3196.

(57) Li, Y. C. L.; Cheng, S.-W.; Chan, T.-W. D. Rapid Commun. Mass Spectrom. 1998, 12, 993-998. 


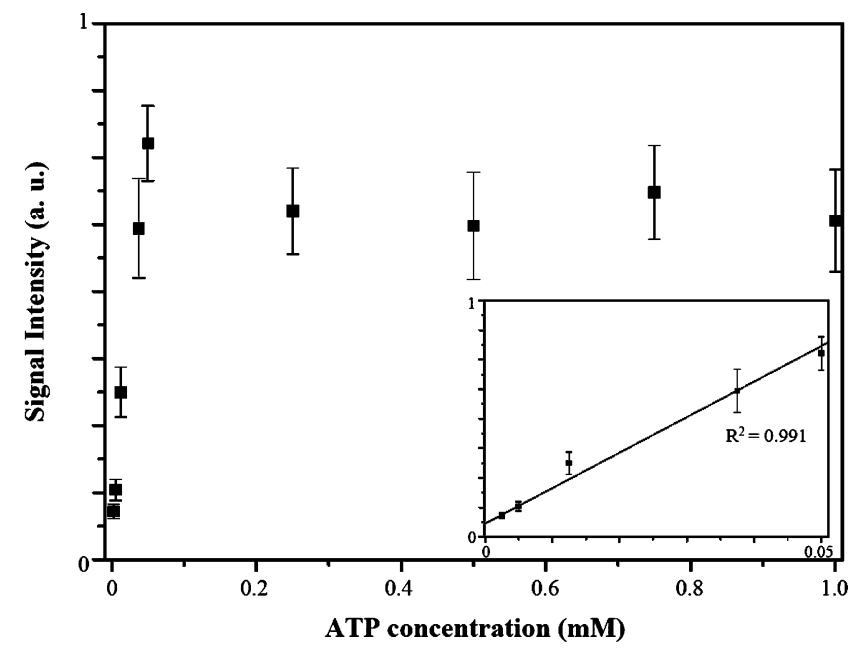

Figure 2. Calibration curve of ATP. AuNPs $(1.5 \times)$ that were resuspended in ammonium citrate solutions (15.0 mM, pH 6.0) containing $15.0 \mu \mathrm{M}$ CTAB were used as comatrixes for the SALDIMS analyses. The inset provides the linearity of the MS signals for [ATP $-\mathrm{Pi}^{-}$against ATP concentrations in the range of 2.5$50.0 \mu \mathrm{M}$.

maximum value of 3.8 . Thus, $15.0 \mathrm{mM}$ ammonium citrate was chosen from herein.

The interaction between ATP and AuNPs and the ionization efficiency of ATP adsorbed on AuNPs are dependent on the charged densities of ATP and AuNPs. The AuNPs at $\mathrm{pH}$ values below 4.0 are not stable and thus were not used in this study. With increasing the $\mathrm{pH}$ value from 4.0 to 6.0, ATP signal intensities increase (See Figure S1B in the Supporting Information), mainly because of increases in the negatively charged densities on the AuNP surface $\left(\mathrm{p} K_{\mathrm{a} 2}\right.$ and $\mathrm{p} K_{\mathrm{a} 3}$ for citric acid are 4.4 and 5.7, respectively; $\mathrm{p} K_{\mathrm{a} 4}$ for ATP is 6.6) ${ }^{58}$ Ionization suppression due to increased ionic strength in the system is the main contributor to decreased MS signals at $\mathrm{pH}>6.0$. The signal intensities decreased dramatically at $\mathrm{pH}>8.0$, which is mainly due to the instability of AuNPs. Figure S1C (in the Supporting Information) displays the impact of CTAB on the signal intensities of ATP. At $15.0 \mu \mathrm{M}$ $\mathrm{CTAB}$, the signals for ATP ions were optimized. Ionization suppression due to increased ionic strength in the system is again the main contributor to decreased MS signals at CTAB > $15.0 \mu \mathrm{M}$.

Quantitative Analysis of ATP by SALDI-MS Using AuNPs. MS-SALDI and SALDI-MS quantifications are generally considered to be unreliable procedures because of poor intra- (sample-tosample) and intersample (spot-to-spot and shot-to-shot signal) preparation reproducibility. To test the feature of AuNPs in this respect, we compared the quantitative determination of ATP by SALDI-MS using AuNPs and MALDI-MS using DHB. SALDI-MS provided smaller variations of the MS intensities for the [ATP $\mathrm{Pi}^{-}$and $[\mathrm{ATP}-\mathrm{H}]^{-}$ions than did MALDI-MS; $10-20 \%$ versus greater than $60 \%$ over 50 sample spots. ${ }^{59}$ The calibration curve of ATP quantified by SALDI-MS using AuNP is displayed in Figure 2, and the inset provides the linearity of the MS signals for $[\mathrm{ATP}-\mathrm{Pi}]^{-}$against ATP concentrations. The correlation

(58) McElroy, W. D.; Glass, B. Phosphorus Metabolism; Johns Hopkins University Press: Baltimore, MD, 1951.

(59) Muddiman, D. C.; Gusev, A. I.; Proctor, A.; Hercules, D. M.; Venkataramanan, R.; Diven, W. Anal. Chem. 1994, 66, 2362-2368. coefficient $\left(R^{2}\right)$ was 0.991 for the determinations of ATP in the concentration range of $2.5-50.0 \mu \mathrm{M}$. The limit of detection (LOD) for ATP at a S/N of 3 was $2.1 \mu \mathrm{M}$. Because the saturated coverage concentration of ATP on AuNP surfaces is $50.0 \mu \mathrm{M}$, the MS signals of ATP at a concentration greater than that approached the plateau. We emphasize that SALDI-MS using AuNPs provides better sensitivity (about 2.7-fold) than does MALDI-MS using DHB. The improved sensitivity using AuNPs as the matrix is a result of greater molar matrix-to-analyte ratios ca. $10^{2}$ to $10^{4}$ analytes/ particles versus $10^{3}$ to $10^{5}$ matrix molecules/analyte. In other words, AuNPs have the capacity to ionize more than one analyte per laser pulse or they have the potential to regenerate to a matrix"active" state between each laser pulse. ${ }^{23}$ We also point out that using AuNPs as SALDI matrixes provides a potentially precise and time-saving procedure for the quantitative assays of ATP; it obviates the need to conduct calibrations using internal standards and avoids the problems associated with the inhomogeneity of the mixture.

ATP Capture in the Presence of GSH Using Apt-AuNPs. In order to further improve the SALDI-MS sensitivity, we tested the possibility of using AuNPs as selective captures for ATP from a solution in the presence of GSH $(20.0 \mu \mathrm{M})$. Unfortunately, we did not detect ATP $(20.0 \mu \mathrm{M})$, mainly because the AuNP surfaces were saturated with GSH, which has stronger interactions than ATP with AuNPs. ${ }^{37,60,61}$ To test our reasoning, we detected the MS signals of GSH in a positive-ion detection mode. The peaks detected at $m / z 330.07$ and 346.03 (not shown) are assigned for $[\mathrm{GSH}+\mathrm{Na}]^{+}$and $[\mathrm{GSH}+\mathrm{K}]^{+}$, respectively, which support a strong interaction between AuNP and GSH through $\mathrm{Au}-\mathrm{S}$ bonding. The color of the solution changed from wine-red to purple-red as a result of GSH-induced aggregation of AuNPs, which also supports our reasoning mentioned above. In order to capture (concentrate) ATP from complex biological samples, a 5'-thiol-modified ATP-binding aptamer that has a specific affinity $\left(K_{\mathrm{d}} \sim 6 \mu \mathrm{M}\right)$ with ATP was introduced to AuNPs. ${ }^{42,43}$ The ATPbinding aptamer was covalently attached to the surfaces of AuNPs through Au-S bonding $(\sim 30 \mathrm{kcal} / \mathrm{mol})$. In this study, the thusprepared bioconjugated AuNP is denoted to be Apt-AuNP. The Apt-AuNPs are highly stable (no detectable decomposition after 3 months as evidence by TEM images and UV-vis absorption spectra) when the solution was stored in a refrigerator at $4{ }^{\circ} \mathrm{C} .{ }^{47}$ By adding ATP at the concentration of $25.0 \mu \mathrm{M}$ to $16.0 \mathrm{mM}$ Tris$\mathrm{HCl}$ solutions ( $\mathrm{pH} 7.6$ ) containing $14.0 \mathrm{mM} \mathrm{KCl}, 4.0 \mathrm{mM} \mathrm{MgCl}_{2}$, and Apt-AuNPs, significant aggregation of Apt-AuNPs induced by ATP took place. The color of the solution as displayed in Figure 3 changed from wine-red to bluish-gray within $10 \mathrm{~min}$ as a result of aggregation. The TEM images (Figure 3, parts A and B) show clearly the differences between Apt-AuNPs in the absence and presence of $25.0 \mu \mathrm{M}$ ATP. With further increasing ATP concentration, aggregation of Apt-AuNPs decreased. The wine-red color of the Apt-AuNP solutions remained when the concentration of ATP was greater than $0.15 \mathrm{mM}$ (data not shown). The interparticle cross-linking of the Apt-AuNPs at low concentrations of ATP was likely through the formation of G-tracts between interoligomers with the join of ATP. Magnesium ions having high affinity toward phosphate backbones further reduce

(60) Chen, S.-J.; Chang, H.-T. Anal. Chem. 2004, 76, 3727-3734.

(61) Tseng, W.-L.; Lee, K.-H.; Chang, H.-T. Langmuir 2005, 21, 10676-10683. 

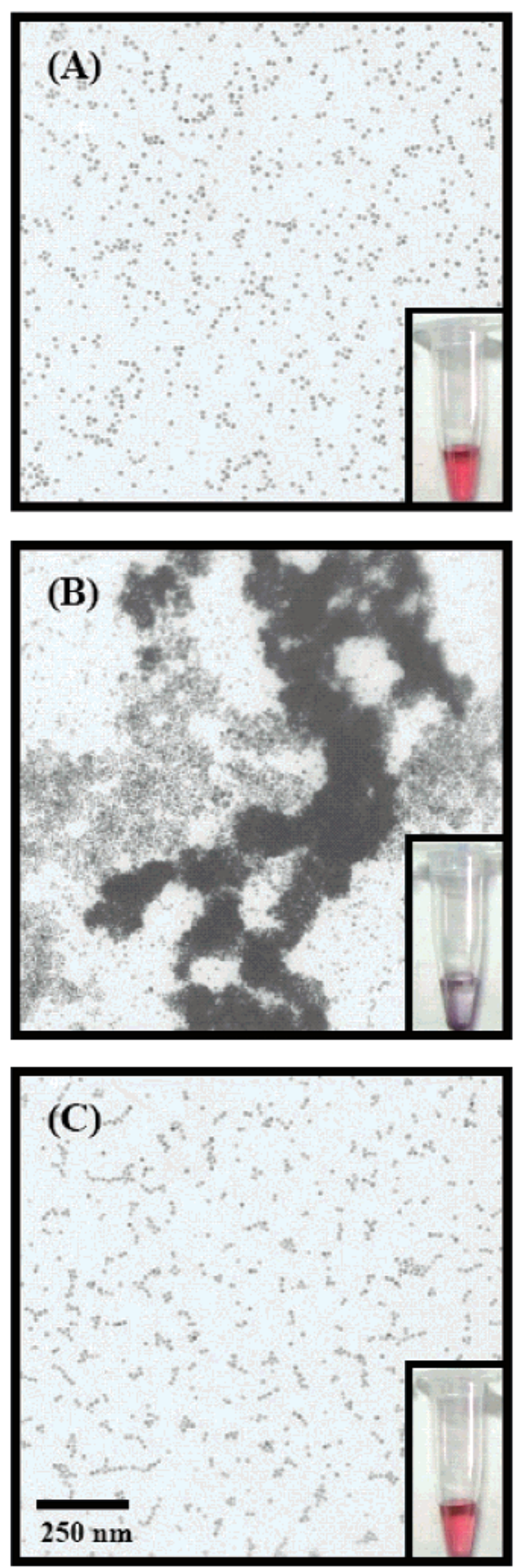

Figure 3. Colors and TEM images of the as-prepared Apt-AuNPs in the (A) absence and (B) presence of $25.0 \mu \mathrm{M}$ ATP. Buffer condition: $16.0 \mathrm{mM}$ Tris- $\mathrm{HCl}$ buffer $(\mathrm{pH} 7.6)$ containing $14.0 \mathrm{mM}$ $\mathrm{KCl}$ and $4.0 \mathrm{mM} \mathrm{MgCl}$. (C) TEM image of ATP/Apt-AuNPs after the sample was subjected to three centrifugation-washing cycles and dispersion in $15.0 \mathrm{mM}$ ammonium citrate solution ( $\mathrm{pH} \mathrm{6.0).}$

the electrostatic repulsions among Apt (Apt-AuNPs) and stabilize these quadruplex structures. At higher ATP concentrations, excess ATP (negative ions) were also adsorbed on the AuNP surface, which increased the $\xi$-potential of the Apt-AuNPs, and thus ATPinduced aggregation reduced. ${ }^{62}$ After thorough centrifugationwashing steps (three cycles), Apt-AuNPs were suspended in 15.0 $\mathrm{mM}$ ammonium citrate ( $\mathrm{pH} 6.0)$. The color of the solution changed back to wine-red, and the particles were well-dispersed as

(62) Huang, C.-C.; Chang, H.-T. Chem. Commun. 2007, 12, 1215-1217. displayed in Figure 3C. In the citrate solution, the interactions between Apt-AuNPs and ATP become weaker, mainly because of changes in the aptamer structure and thus loss of its affinity toward ATP. We note that the conformational structure of the aptamer is sensitive to the ionic strength. ${ }^{63,64}$ The result clearly reveals that the interaction between ATP and Apt-AuNPs is reversible.

The MS spectrum depicted in Figure S2A (in the Supporting Information) shows that no peaks for ATP ions were detected when Apt-AuNPs were used directly to assist desorption/ ionization of ATP. In the MS region, we did not observe any peaks for the aptamer and its fragments, minimizing its interference. Through the interactions of the DNA bases with AuNPs, parts of the oligonucleotides would lie flat on the surfaces of AuNPs. We suggest that the loss of MS signals for ATP and aptamer is mainly due to the fact that energy transferred from AuNPs toward these molecules is ineffective in the presence of oligonucleotides adsorbed on the surfaces. The average aptamer surface coverage on AuNP was ca. $27 \mathrm{pmol} / \mathrm{cm}^{2}$, which is slightly lower than the value of $35 \mathrm{pmol} / \mathrm{cm}^{2}$ for the chemisorption of alkanethiolmodified 33-mer oligonucleotides on $15.7 \mathrm{~nm}$ diameter AuNPs. ${ }^{48}$ To overcome the disadvantages, we add bare AuNPs into the solution, based on the fact that AuNPs are effective SALDI matrixes for ATP as exhibited in Figure 1B. As expected, Figure S2B (in the Supporting Information) demonstrates the success of our strategy. The released ATP ions were captured by the bare AuNPs. Scheme 1 summarizes the two-step sample preparation for MS analysis of ATP by SALDI-MS using AptAuNPs and AuNPs. Apt-AuNPs are selective capturers of ATP, and AuNPs are effective LDI matrixes.

Selectivity and Sensitivity of ATP Analysis. Aqueous solution containing $0.1 \mathrm{mM}$ guanosine triphosphate, cytidine triphosphate, and uridine triphosphate was used to test the selectivity of the present method using Apt-AuNPs. As expected, there were no peaks corresponding to the three analyte ions in the MS spectra (not shown). This result demonstrates that Apt-AuNPs are selective toward ATP, which agrees with the fact that the aptamer is specific toward ATP.

Figure S3 displays the quantitative determination of ATP when using Apt-AuNPs as the probes and AuNPs as the SALDI matrixes; the inset exhibits the linearity of the MS signals of [ATP - Pi] ${ }^{-}$ions against ATP concentration over the range of 10.0$125.0 \mu \mathrm{M}$. The correlation coefficient $\left(R^{2}\right)$ was 0.994 , and the LOD at a $\mathrm{S} / \mathrm{N}$ ratio of 3 was $7.5 \mu \mathrm{M}(7.5 \mathrm{pmol})$. The absolute amounts of ATP and GSH in single cells are both in the levels of fmol, and thus this approach does not provide enough sensitivity for the detection of GSH and ATP in single cells. The LOD is higher than that using AuNPs, mainly because of loss of ATP during sample preparation. It was our expectation that the loss in sensitivity could be overcome by utilizing the advantages of the Apt-AuNPs as selective and concentrating probes. To test the hypothesis, we added $50.0 \mu \mathrm{L}$ of Apt-AuNPs $(2.5 \times)$ to a $0.45 \mathrm{~mL}$ of solution containing $1.0 \mu \mathrm{M}$ ATP, then conducted three centrifugationwashing cycles to remove unbound ATP, and finally prepared the pellets in $15.0 \mathrm{mM}$ ammonium citrate containing AuNPs and CTAB prior to SALDI-MS measurements. At such a low ATP

(63) Wang, J.; Jiang, Y.; Zhou, C.; Fang, X. Anal. Chem. 2005, 77, 3542-3546. (64) André, C.; Xicluna, A.; Guillaume, Y.-C. Electrophoresis 2005, 26, 32473255 . 
Scheme 1. Illustration of the Interactions of ATP with Apt-AuNPs and AuNPs

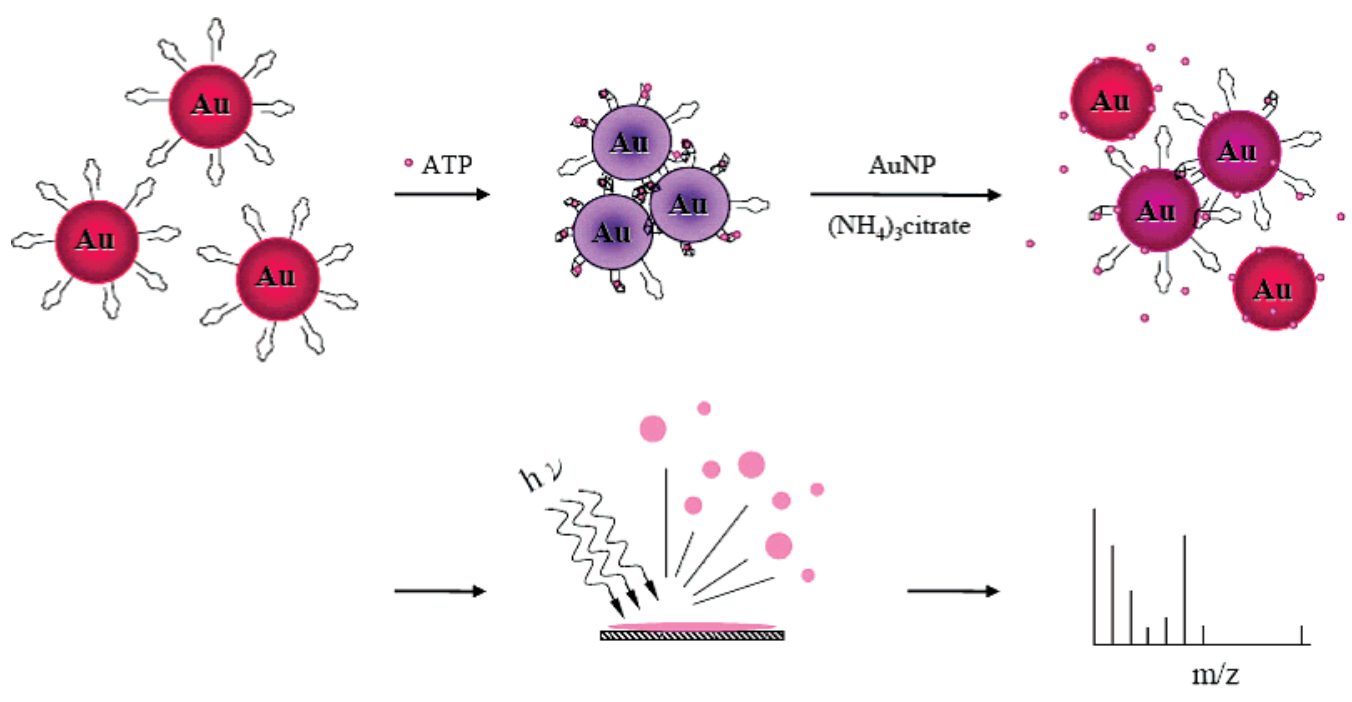

Auf: AuNP $\because$ :ATP

concentration, ATP only slightly induced aggregation of AuNPs, and thus no precipitation occurred. To collect Apt-AuNPs, centrifugation (8000 rpm for $10 \mathrm{~min}$ ) prior to SALDI-MS measurements is essential. Without conducting centrifugation, there are no peaks assigned for $[\mathrm{ATP}-\mathrm{Pi}]^{-}$and $[\mathrm{ATP}-\mathrm{H}]^{-}$in the MS spectrum exhibited in Figure 4A. Two peaks for $[\mathrm{ATP}-\mathrm{Pi}]^{-}$and [ATP $-\mathrm{H}]^{-}$are apparent in the MS spectrum depicted in Figure $4 \mathrm{~B}$ after the sample solution was subjected to concentration by a factor of 50 . Based on the peak heights of the signals of the [ATP - Pi $]^{-}$ions in this MS spectrum, we estimated the LOD for ATP to be $0.48 \mu \mathrm{M}$. The results indicate that the sensitivity improvement of SALDI-MS using Apt-AuNPs and AuNPs for ATP is 17 -fold when compared to that obtained under the condition described in Figure S3. Although the sensitivity improvement of SALDI-MS using Apt-AuNPs and AuNPs is not as expected

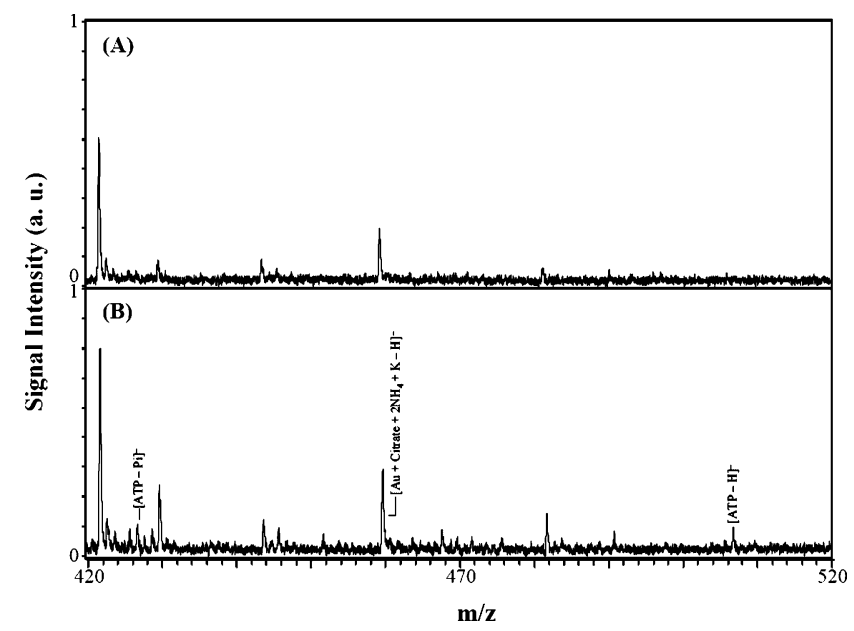

Figure 4. Mass spectra of ATP using $0.25 \times \mathrm{Apt}-\mathrm{AuNPs}$ as probes (A) without concentration of the samples $(1.0 \mu \mathrm{M}, 0.5 \mathrm{~mL})$ and $(B)$ with concentration by a factor of $50 \times$. AuNPs $(1.5 \times)$ that were prepared in ammonium citrate solutions $(15.0 \mathrm{mM}, \mathrm{pH} 6.0)$ containing $15.0 \mu \mathrm{M}$ CTAB were used as LDI matrixes for the SALDI-MS analyses. (50-fold), interferences from a variety of solutes such as thiol compounds are suppressed. We also emphasize that the sensitivity improvement can be further improved if larger volumes of samples are used.

Determination of ATP and GSH in a Cultured Cell Extract. We tested the practicality of SALDI-MS using Apt-AuNPs and AuNPs for simultaneous analysis of ATP and GSH in cell extract samples. To minimize protein interferences in ATP-induced AuNPs aggregation and suppression of ATP ionization, the cell lysates were subjected to deproteination by filtration using cutoff membranes. After addition of both Apt-AuNPs and AuNPs into the deproteinized cell lysates to trap ATP and GSH, the mixtures were subjected to three centrifugation-washing cycles to minimize the interference from other solutes and salts. The precipitates were then resuspended in an ammonium citrate solution $(15.0 \mathrm{mM}, \mathrm{pH}$ 6.0) containing AuNPs and CTAB. As mentioned above, ATP is favorably detected in a negative-ion detection mode, while GSH is preferably detected in a positive-ion detection mode. Thus, we applied positive and negative MS modes for analysis of the samples. Representative MS spectra are depicted in Figure 5. Figure $5 \mathrm{~A}$ clearly displays two peaks for the $[\mathrm{ATP}-\mathrm{Pi}]^{-}$and $[\mathrm{ATP}-\mathrm{H}]^{-}$ions. By using a standard addition method (plotting the peak height at $m / z 426.20$ against the spiked ATP concentration in the range of $0-0.1 \mathrm{mM}$ ), we estimated that the concentration of ATP in the cell lysate is $1.9( \pm 0.3) \mathrm{mM}(n=3)$ after consideration with the dilution factor of $50 \times$; this value agrees with the normal level of ATP between 2 and $10 \mathrm{mM}$ in cells. ${ }^{65}$ For comparison, MALDI-MS using DHB was conducted for the analysis of the same sample. There are no peaks for ATP ions in the MS spectrum depicted in Figure 5B. Figure 5C displays the peaks at $m / z 330.07$ and 346.03 that are assigned to be [GSH + $\mathrm{Na}]^{+}$and $[\mathrm{GSH}+\mathrm{K}]^{+}$ions. In comparison to our previous result, ${ }^{37}$ the spectra quality is relatively poor, mainly due to lower detection

(65) Szewczyk, A.; Pikua, S. Biochim. Biophys. Acta 1998, 1365, 333-353.

(66) Krüger, R.; Pfenninger, A.; Fournier, I.; Gluckmann, M.; Karas, M. Anal. Chem. 2001, 73, 5812-5821. 


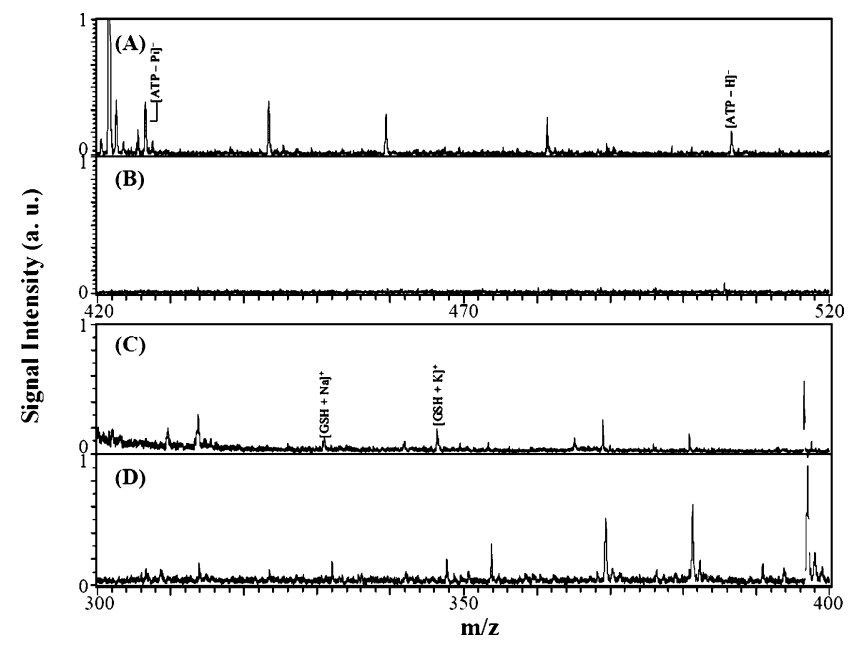

Figure 5. Mass spectra of ATP and GSH in a cell lysate. (A and C) Apt-AuNPs and AuNPs were used both to capture ATP and GSH in deproteinized cell lysate and as matrixes. (B and D) DHB was used as the matrix. Volumes of $1.0 \mu \mathrm{L}$ of ammonium citrate solutions (15.0 $\mathrm{mM}, \mathrm{pH}$ 6.0) containing 15.0 $\mu \mathrm{M}$ CTAB were used as additives. Cells of MDA-MB-231 were subjected to five cycles of centrifugation and washing; the pellets were resuspended in deionized water before cell rupture. Spectra were obtained in (A and B) negative-ion mode and ( $C$ and $D$ ) positive-ion mode, respectively. Laser shots of 240 pulses were applied under a laser energy $67.5 \mu \mathrm{J} /$ pulse. The peaks at $\mathrm{m} / \mathrm{z}$ 444.07, 460.07, and 481.07 in (A) are assigned to be the [Au + citrate $\left.+2 \mathrm{NH}_{4}+\mathrm{Na}-\mathrm{H}\right]^{-},\left[\mathrm{Au}+\text { citrate }+2 \mathrm{NH}_{4}+\mathrm{K}-\mathrm{H}\right]^{-}$, and $[\mathrm{Au}+$ citrate $+\mathrm{NH}_{4}+2 \mathrm{~K}-\mathrm{H}^{-}$ions.

sensitivity when conducting positive-ion measurements at higher $\mathrm{pH}$ values. ${ }^{66}$ We used the peak at 330.07 to quantitatively determine the GSH concentration in the sample. After applying a standard addition, we determined that the GSH concentration in the cell lysate was $0.94( \pm 0.06) \mathrm{mM}(n=3)$; this value is in good

(67) Balendiran, G. K.; Dabur, R.; Fraser, D. Cell Biochem. Funct. 2004, 22, $343-352$.

(68) Kiesslich, T.; Oberdanner, C. B.; Krammer, B.; Plaetzer, K. J. Biochem. Biophys. Methods 2003, 57, 247-251.

(69) Bai, Q. Y.; Zelles, L.; Scheunert, I.; Korte, F. Chemosphere 1988, 17, 24612470.

(70) Handumrongkul, C.; Silva, J. L. J. Food Sci. 1994, 59, 67-69. agreement with the normal levels of GSH between 0.5 and $10 \mathrm{mM}$ in cells. ${ }^{67}$ Again, Figure 5D demonstrates that MALDI-MS using DHB is not a good choice for determination of GSH in the lysate sample. Although the present SALDI-MS approach using AptAuNPs and AuNPs for the analysis of GSH and ATP does not provide the sensitivity as effectively as the fluorescence and chemiluminescence methods, ${ }^{63,68}$ the present approach is almost free of interference and provides molecular information. Because of the important roles that ATP and GSH play in biological systems, the present approach holds great potential for the determinations of microbial activity in soils, ${ }^{69}$ the freshness of a wide variety of fish, ${ }^{70}$ and their resistance to chemotherapeutic drugs ${ }^{67}$ when using ATP and GSH as indicators.

\section{CONCLUSIONS}

In this study, we prepared Apt-AuNPs and used them as selective probes for ATP analysis through SALDI-MS. Apt-AuNPs not only show high affinity toward ATP from mixtures but can also be used to improve the sensitivity of ATP detection by conducting a concentration step. The use of AuNPs as matrixes for the determination of ATP provides a number of advantages over DHB, including simplicity, sensitivity, selectivity, and repeatability. Because AuNPs and Apt-AuNPs provide high selectivities toward GSH and ATP, respectively, they have been used for the analysis of the two analytes in complicated biological samples after simple sample pretreatment (separation is not required). This approach provides the benefits of a low degree of matrix interference and high specificities. Thus, we believe that this approach can accelerate the analysis speed when screening a number of biological samples such as urine and blood.

\section{SUPPORTING INFORMATION AVAILABLE}

Additional information as noted in text. This material is available free of charge via the Internet at http://pubs.acs.org.

Received for review January 4, 2007. Accepted April 18, 2007.

AC070023X 